\title{
Avaliação da influência do tipo de cobrança e da composição do tráfego sobre o desempenho operacional de praças de pedágio
}

\author{
Marta Rodrigues Obelheiro'; Marcelo Leismann de Oliveira ${ }^{2}$; Helena Beatriz Bettella Cybis ${ }^{3}$
}

\begin{abstract}
Resumo: Este trabalho tem por objetivo avaliar o impacto da composição do tráfego e das condições de cobrança na capacidade de praças de pedágio. As variações das condições de cobrança de pedágio avaliadas neste estudo incluem reduções nos tempos de atendimento nas cabines manuais, bem como os impactos decorrentes da adoção, e crescente adesão, dos usuários à cobrança eletrônica de pedágio. As informações sobre tempos de atendimento utilizados no estudo correspondem a dados reais coletados em praças de pedágio do estado do Rio Grande do Sul. As análises foram realizadas a partir da simulação de uma praça de pedágio através do software de microssimulação VISSIM. Os resultados evidenciaram e quantificaram o aumento de capacidade das praças associado ao treinamento de arrecadadores e à adoção de tarifas que facilitam o troco. Neste estudo melhorias associadas a estas medidas corresponderam a um aumento de até $19 \%$ na capacidade da praça. Melhorias bem mais significativas de desempenho, entretanto, podem ser atingidas com o aumento da adesão dos usuários ao sistema de cobrança eletrônica de pedágio.
\end{abstract}

Abstract: This study aims to assess the impact of the composition of traffic and charging conditions on the capacity of toll plazas. The toll charging conditions evaluated in this study include the reductions in service times at manual toll booths, the introduction of electronic toll collection and the increase in electronic collection compliance rates. Service times adopted in this study correspond to data collected at toll plazas of the state of Rio Grande do Sul. Analyses presented in this paper are based on toll plaza simulations through the microsimulation software VISSIM. The simulation outcomes evidenced and quantified the capacity increase associated with collectors training and the adoption of fares that simplified the change. In this study, improvements associated with these measures corresponded to an increase of up to $19 \%$ of the plaza capacity. More significant improvements in performance, however, can be achieved by increasing the compliance of the electronic toll collection system.

\section{INTRODUÇÃO}

O desempenho operacional de praças de pedágio depende de sua capacidade de atendimento, que está diretamente relacionada com os tempos de atendimento dos veículos nas cabines. Sob o ponto de vista da engenharia de tráfego, a cobrança de pedágio geralmente atua como um gargalo ao fluxo nas rodovias, uma vez que a capacidade das praças costuma ser menor do que a capacidade das rodovias onde estas praças estão inseridas. Os veículos são obrigados a parar ou a reduzir suas velocidades para o pagamento da tarifa, tendendo a reduzir de forma significativa a capacidade viária nos trechos em que existem praças de pedágio, com a possível formação de congestionamentos em períodos de pico.

Entretanto, dependendo do número de cabines, da

\footnotetext{
${ }^{1}$ Marta Rodrigues Obelheiro, Laboratório de Sistema de Transportes, Programa de Pós-Graduação em Engenharia de Produção, Universidade Federal do Rio Grande do Sul, Porto Alegre, RS, Brasil. (e-mail: marta.obelheiro@gmail.com).

${ }^{2}$ Marcelo Leismann de Oliveira, Laboratório de Sistema de Transportes, Programa de Pós-Graduação em Engenharia de Produção, Universidade Federal do Rio Grande do Sul, Porto Alegre, RS, Brasil. (e-mail: leismann@producao.ufrgs.br).

${ }^{3}$ Helena Beatriz Bettella Cybis, Laboratório de Sistema de Transportes, Programa de Pós-Graduação em Engenharia de Produção, Universidade Federal do Rio Grande do Sul, Porto Alegre, RS, Brasil. (e-mail: helenabc@producao.ufrgs.br).
}

Manuscrito recebido em 10/5/2010 e aprovado para publicação em 12/8/2010. Este artigo é parte de TRANSPORTES, volume XVIII, número 3, setembro de 2010. ISSN: 2237-1346 (online). alocação dos tipos de cobrança nas cabines e da adesão dos veículos à cobrança eletrônica (ETC - electronic toll collection), a praça de pedágio pode vir a ter uma capacidade igual ou até mesmo maior do que a capacidade da rodovia na qual está inserida (Aycin, 2006).

Assim, o estudo da operação das praças de arrecadação de pedágio pode fornecer informações importantes para subsidiar decisões quanto à racionalização destes sistemas, resultando em um aumento do conforto percebido pelos usuários da rodovia e até mesmo em melhorias no desempenho econômico da concessão.

Este artigo tem por objetivo avaliar o efeito do tipo de cobrança e da composição do tráfego sobre o desempenho operacional de uma praça de pedágio. O estudo foi desenvolvido através da simulação de uma praça de pedágio com o uso do software de microssimulação VISSIM (PTV, 2006).

\section{CAPACIDADE DE ATENDIMENTO DE PRAÇAS DE PEDÁGIO}

A capacidade de uma cabine de pedágio pode ser definida como o máximo fluxo horário de veículos que pode atravessar esta cabine, de acordo com as condições mais frequentes de tráfego e da via (Lin e Su, 1994). A capacidade está diretamente relacionada aos tempos de atendimento dos veículos nas cabines, que por sua vez dependem de fatores como valor da tarifa, 
forma de pagamento, fluxo e classes de veículos e também da atuação de arrecadadores e motoristas (Oliveira, 2004; Araújo, 2001). A influência destes fatores sobre os tempos de atendimento pode ocorrer de diferentes formas.

A intensidade do fluxo de veículos exerce influência sobre os tempos de atendimento à medida que, em condições de fluxos altos com formação de filas, o tempo de espera na fila é frequentemente utilizado pelos motoristas para procurar o valor exato da tarifa antes do pagamento. Por outro lado, em condições de fluxos muito baixos, os operadores tendem a consumir mais tempo atendendo os veículos do que quando pressionados por filas crescentes. Evidências desse comportamento são referenciadas na literatura por Woo e Hoel (1991) e Oliveira et al. (2003).

A composição do fluxo também afeta o desempenho e capacidade de praças de pedágio. Veículos pesados, como caminhões e ônibus, apresentam tempos de atendimento significativamente maiores que os tempos de atendimento registrados para automóveis. Ainda, veículos pesados e automóveis apresentam diferentes relações peso-potência, influenciando nas acelerações e desacelerações dos veículos nas cabines (Araújo e Setti, 2006; Oliveira, 2004).

Os valores das tarifas cobradas em praças de pedágio sofrem constantes atualizações. As revisões de tarifas podem gerar impactos nos tempos de atendimentos e consequentemente no desempenho e capacidade das praças. A adoção de tarifas com valores inteiros leva a significativas reduções nos tempos de atendimento, uma vez que o cálculo do troco pelo arrecadador é simplificado, bem como a verificação do mesmo pelo motorista (Araújo e Setti, 2006).

O perfil dos motoristas pode influenciar no desempenho de praças de pedágio, em particular, em função da frequência com que utilizam a rodovia. Motoristas que utilizam uma via habitualmente tendem a apresentar tempos de atendimento menores, por possuírem conhecimento prévio sobre os locais das praças e tarifas (Araújo e Setti, 2006).

Existe em todo o mundo uma tendência à expansão de métodos de cobrança automatizados. A forma de cobrança tem, certamente, o impacto mais significativo nos tempos de processamento dos veículos em estruturas de pedágio. Os tempos de atendimento diminuem à medida que aumenta a automação da forma de pagamento. Desta forma, os pagamentos em dinheiro apresentam os maiores tempos de atendimento, enquanto a cobrança eletrônica apresenta os menores tempos de atendimento (Araújo e Setti, 2006; Oliveira, 2004).

A importância relativa destes vários fatores, assim como mecanismos para aperfeiçoar o desempenho das praças de pedágio, têm sido continuamente avaliados.
Operadoras de concessões rodoviárias procuram constantemente aperfeiçoar o desempenho operacional das praças, seja devido aos altos custos operacionais, ou devido à necessidade de atendimento a cláusulas contratuais que definem os tempos de atendimento e comprimentos de filas máximos aceitáveis, ou ainda para melhorar a imagem da empresa diante dos usuários, reduzindo a insatisfação causada pelo tempo de viagem adicional devido a esperas nas filas.

\section{ESTUDO DE CASO}

Este artigo apresenta um estudo de caso no qual foi avaliado o desempenho de uma praça de pedágio frente a diferentes condições de operação, que envolvem: (i) variações nos tempos de atendimento e (ii) utilização de cobrança eletrônica. A praça de pedágio analisada opera em condições de pagamento manual, e os tempos de atendimento considerados foram observados por uma concessionária após uma alteração de tarifas e um processo de treinamento dos arrecadadores. Foram também avaliados os impactos no desempenho operacional desta praça decorrentes da introdução e crescente adesão dos usuários a um sistema de cobrança eletrônica.

A avaliação do desempenho da praça frente às condições de operação analisadas foi realizada mediante a utilização de cenários. A primeira análise refere-se ao impacto na capacidade da praça em decorrência de uma variação nos tempos de atendimento praticados nas cabines. Nestes cenários, a praça opera com todas as cabines em regime de cobrança manual. A segunda análise busca avaliar a influência da introdução de cobrança eletrônica e da crescente adesão dos usuários a este tipo de cobrança. Assim, foram construídos cenários com a substituição de uma cabine manual por uma cabine dedicada à cobrança eletrônica. O desempenho operacional da praça foi avaliado para diferentes taxas de utilização da cabine eletrônica: 10\% (taxa de utilização atual), 30\% e 40\%. Valores maiores do que $40 \%$ não foram testados, uma vez que provavelmente envolveriam a adoção de mais cabines dedicadas a este tipo de cobrança. A análise é realizada a partir da simulação de uma praça de pedágio através da utilização do software VISSIM.

\subsection{Dados utilizados no estudo}

A praça de pedágio analisada é representativa das praças encontradas no estado do Rio Grande do Sul, no que se refere ao número de cabines e às formas de cobrança praticadas. Os dados sobre tempos de atendimento dos veículos nas cabines de cobrança manual foram extraídos de dois bancos de dados fornecidos por uma concessionária do estado do Rio Grande do Sul. 
Os bancos de dados fornecidos são resultado de duas pesquisas de campo em 14 praças de pedágio, sendo a primeira realizada no ano de 2003 e a seguinte realizada no ano de 2004. A pesquisa de 2003 resultou na observação de 54.780 veículos. A pesquisa de 2004 resultou na observação de tempos de atendimento de 57.580 veículos. Em ambas as pesquisas, foram registrados, para cada veículo, a sua categoria, o tempo de atendimento na cabine e a forma de pagamento praticada. As formas de pagamento registradas foram dinheiro e cartão. Os pagamentos realizados com cartão incluem cartão de vale-pedágio, cartão de isenção da tarifa (fornecido pela concessionária) e cartão de pagamento da concessionária.

Além das cabines de cobrança manual (dinheiro/cartão), são operadas pela concessionária cabines de cobrança eletrônica. Estas cabines são adaptadas a partir de cabines de cobrança manual, e a passagem dos veículos somente é liberada mediante a abertura de uma cancela, assim como ocorre nas demais cabines. A velocidade máxima sinalizada para as faixas com cabine eletrônica é de $30 \mathrm{~km} / \mathrm{h}$, ainda que a tecnologia utilizada na identificação de veículos permita velocidades bastante superiores a este valor (cerca de $100 \mathrm{~km} / \mathrm{h}$ ). A capacidade destas cabines fica em torno de 1100 veículos/hora, segundo a concessionária. Este tipo de cabine atende atualmente cerca de $10 \%$ dos usuários das praças.

\subsection{Modelagem e calibração da rede}

O VISSIM é um modelo de simulação de tráfego microscópico estocástico, capaz de representar o comportamento do tráfego em rodovias. O modelo adotado para representar movimentos longitudinais de veículos (car-following) apresenta características psicofísicas, baseado no trabalho de Wiedemann (1991), o qual combina um modelo de percepção de motoristas com modelos de desempenho de veículos. O modelo representativo de movimentos transversais dos veículos (lane-changing) é um algoritmo baseado em regras (PTV, 2006).

\subsubsection{Modelagem da rede}

Esta pesquisa envolveu a modelagem de duas redes de tráfego que representam praças de pedágio de 10 cabines, através do software de microssimulação VISSIM versão 4.30-05 (PTV, 2006). A primeira rede representou uma praça de pedágio com 10 cabines de cobrança manual, ou seja, os tempos de atendimento eram representativos de tempos relativos a pagamentos em dinheiro e cartões. A segunda rede, ilustrada pela Figura 1, modelou uma praça de pedágio com 9 cabines de cobrança manual (dinheiro/cartão) e 1 cabine de cobrança eletrônica. As duas redes modeladas mantiveram um total de 10 cabines e a mesma geometria geral da praça.
As composições de tráfego dos diversos cenários simulados neste estudo foram compostas por três classes de veículos: (i) automóveis, (ii) caminhões leves e (iii) caminhões pesados. Na rede modelada apenas com cabines de cobrança manual, foram simuladas duas composições de tráfego, representando fluxos compostos somente por automóveis e fluxos compostos por automóveis e caminhões. Na rede composta pela praça de pedágio com cabine eletrônica, foi simulada somente uma composição de tráfego, composta apenas por automóveis.

A categoria de caminhões foi dividida em duas clas-

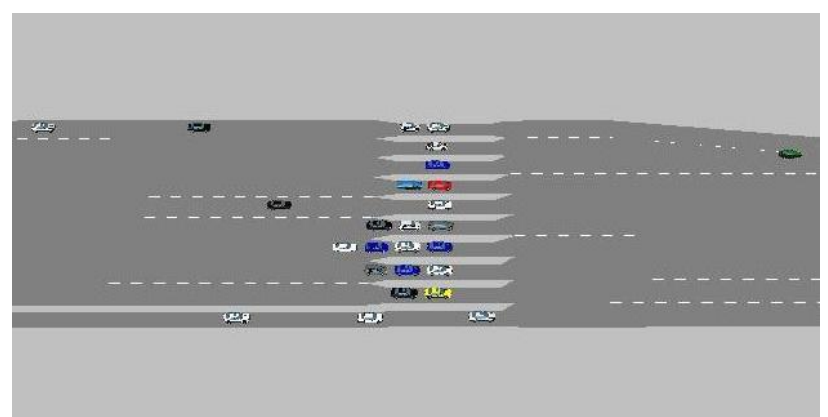

Figura 1. Imagem representativa da praça de pedágio com cabine eletrônica

ses devido ao impacto deste tipo de veículo (i) na formação e comprimento de filas nas cabines; (ii) no tempo de processamento de veículos nas cabines. A Tabela 1 mostra as características das duas classes de caminhões consideradas, de acordo com o Manual de Estudos de Tráfego do DNIT (DNIT, 2006).

Tabela 1. Características dos tipos de caminhões usados na modelagem

\begin{tabular}{lccc}
\hline & $\begin{array}{l}N^{\boldsymbol{o}} \text { de } \\
\text { eixos }\end{array}$ & $\begin{array}{c}\text { Comprimento } \\
\text { máx } \\
(\boldsymbol{m})\end{array}$ & $\begin{array}{c}\text { Peso Bruto } \\
\text { Total máx } \\
\text { (ton) }\end{array}$ \\
\hline Caminhões leves & 2 e 3 & 14,0 & 23 \\
\hline Caminhões pesados & 5 e 6 & 19,8 & 57 \\
\hline
\end{tabular}

Dados sobre tempos de atendimento dos veículos nas cabines de cobrança manual foram extraídos de dois bancos de dados fornecidos por uma concessionária do estado do Rio Grande do Sul. O tempo de atendimento medido corresponde ao tempo compreendido entre o momento em que o veículo atinge a posição de pagamento em frente à cabine de cobrança e o momento em que a cancela desce após a sua passagem. Esta forma de medição de tempos de atendimento foi padronizada pela concessionária, com base em trabalho de Araújo (2001), tendo sido utilizada nas pesquisas que geraram os dois bancos de dados citados neste trabalho.

A partir dos bancos de dados, foram obtidos valores de tempos de atendimento de automóveis, caminhões leves e caminhões pesados, além de informações sobre tarifas e composições do fluxo de tráfego. Através da 
análise dos dados, verificou-se que a categoria de caminhões era composta por, aproximadamente, 2/3 de caminhões leves e 1/3 de caminhões pesados. Esta proporção foi mantida na modelagem das redes.

As Tabelas 2 e 3 apresentam os tempos de atendimento obtidos nas pesquisas realizadas pela concessionária nos anos de 2003 e 2004. Foram realizadas análises para verificar se existiam diferenças estatisticamente significativas entre as médias de tempos de atendimento de automóveis, caminhões leves e caminhões pesados, para os dados correspondentes às duas pesquisas. Ao nível de significância de $5 \%$, e para ambas as pesquisas, verificou-se que existem diferenças estatisticamente significativas entre as médias dos tempos de atendimento das categorias analisadas. Além disso, foram realizadas análises para verificar se existiam diferenças estatisticamente significativas entre as médias de tempos de atendimento referentes aos dois bancos de dados, por tipo de veículo. Ao nível de significância de 5\%, e para todas as categorias de veículos, verificou-se que existem diferenças estatisticamente significativas entre as médias dos tempos de atendimento dos dois bancos de dados analisados.

Os dados apresentados nas Tabelas 2 e 3 mostram que houve uma redução nos tempos médios de atendimento de automóveis e caminhões entre os anos de 2003 e 2004. Esta redução é resultado da adoção de tarifas que passaram a facilitar o troco e de um treinamento dos arrecadadores, que teve como objetivo aumentar a eficiência da cobrança manual.

\subsubsection{Calibração da rede}

As duas redes de tráfego tiveram dados e parâmetros calibrados de maneira idêntica, à exceção dos parâmetros relativos à cabine de cobrança eletrônica, existente em apenas uma das redes. Nas cabines de cobrança manual, foram calibrados parâmetros de tempos de atendimento, espaçamentos entre veículos em filas, desacelerações e velocidades esperadas. Na cabine de cobrança eletrônica, o processo de calibração visou reproduzir a capacidade de atendimento desta cabine e velocidades dos veículos ao passar pela área de cobrança.

Para a calibração das redes, dados sobre acelerações, desacelerações e tempos de percurso dos veículos em praças de pedágio foram extraídos de um trabalho desenvolvido por Araújo (2001), que analisou características operacionais de praças de pedágio no estado de São Paulo.

Para calibrar os tempos de percurso nas chegadas das praças, os modelos foram codificados de modo a incluir arcos de 300 metros a montante das cabines, correspondendo à área de aproximação, de forma a representar uma situação semelhante à observada em trabalho de Araújo (2001). Valores de velocidades desejadas de todas as categorias de veículos foram sistematicamente modificados com o objetivo de obter tempos de percurso observados em campo. Para a verificação da compatibilidade dos tempos de percurso simulados com os tempos retirados do trabalho de Araújo (2001), foi calculado o Erro Relativo Absoluto Médio (ERAM). Após a calibração, os ERAMs calculados para tempos médios de percurso de automóveis e caminhões foram, respectivamente, 5,88\% e 5,90\%, sendo considerados satisfatórios para os objetivos do trabalho.

A rede representativa da praça de pedágio com cabine eletrônica foi calibrada de forma a atingir uma capacidade de atendimento nas simulações semelhante à capacidade informada pela concessionária para faixas com este tipo de cobrança, em torno de 1100 veículos/hora. Com o objetivo de ajustar a velocidade de passagem pela área de cobrança, foram inseridos arcos com velocidades reduzidas, de forma a induzir nos veículos uma redução gradual da velocidade, chegando a cerca de $30 \mathrm{~km} / \mathrm{h}$ ao passar pela cabine (velocidade sinalizada nas praças de pedágio).

Com os tempos de atendimento inseridos nos mode-

Tabela 2. Tempos de atendimento usados nas modelagens (Ano de 2003)

\begin{tabular}{lcccc}
\hline & \multirow{2}{*}{ Observações (n) } & \multirow{2}{*}{ Fração da Coleta } & \multicolumn{2}{c}{ Tempos de Atendimento (s) } \\
\cline { 4 - 5 } & & & Média & Desvio Padrão \\
\hline Totalidade dos dados & 54.780 & $100,00 \%$ & 28,38 & 5,20 \\
Automóveis & 35.735 & $65,23 \%$ & 24,99 & 10,47 \\
Caminhões Leves - 2 e 3 eixos & 12.175 & $22,23 \%$ & 29,09 & 11,14 \\
Caminhões Pesados - 5 e 6 eixos & 4.042 & $7,38 \%$ & 33,56 & 10,67 \\
\hline
\end{tabular}

Tabela 3. Tempos de atendimento usados nas modelagens (Ano de 2004)

\begin{tabular}{lcccc}
\hline & Observações (n) & Fração da Coleta & \multicolumn{2}{c}{ Tempos de Atendimento (s) } \\
\cline { 3 - 5 } & & Média & Desvio Padrão \\
\hline Totalidade dos dados & 57.580 & $100,00 \%$ & 25,68 & 13,12 \\
Automóveis & 34.929 & $60,66 \%$ & 20,29 & 7,57 \\
Caminhões Leves - 2 e 3 eixos & 13.665 & $23,73 \%$ & 25,07 & 9,47 \\
Caminhões Pesados - 5 e 6 eixos & 4.897 & $8,50 \%$ & 30,78 & 9,95 \\
\hline
\end{tabular}


los, e após a calibração dos tempos de percurso nas chegadas das praças, foram realizados testes a fim de verificar visualmente o comportamento dos modelos. Foi constatado que, quando em fila nas cabines de cobrança manual, os veículos apresentavam espaçamentos ligeiramente maiores do que o visualmente esperado. Por outro lado, na faixa com cabine eletrônica, os veículos trafegavam com espaçamentos bem menores do que o visualmente esperado.

$\mathrm{O}$ algoritmo de car-following utilizado nas modelagens apresenta diversos parâmetros de calibração, entre eles o parâmetro que regula a distância de parada entre veículos (chamado CC0), cujo valor padrão é de 1,5 metros. Desta forma, para ajustar o espaçamento entre veículos, o parâmetro CC0 foi alterado. Nas cabines de cobrança manual, o parâmetro teve seu valor ajustado para 1,2 metros, como forma de diminuir os espaçamentos de veículos em filas. Na faixa com cabine de cobrança eletrônica, este parâmetro teve seu valor aumentado para 2,0 metros. Além disso, o parâmetro que representa o headway entre veículos (chamado CC1) também foi ajustado para o tráfego nesta faixa. O valor padrão do software para este parâmetro é de 0,9 segundos, sendo aumentado para 1,8 segundos.

Após a calibração, os modelos passaram a apresentar comportamentos visualmente esperados para situações de tráfego e filas, sendo considerados aptos a representar o comportamento dos veículos em praças de pedágio.

\section{ANÁLISE DOS RESULTADOS}

Para avaliar o desempenho operacional da praça de pedágio frente às diversas condições de operação, foram realizadas simulações com diferentes intensidades de fluxo, durante períodos de 1 hora. Os dados dos 15 minutos iniciais de cada rodada foram descartados devido ao efeito de warm-up nas redes. Através das simulações, foram estimados o número de veículos processados nas cabines por intervalo de tempo e o tamanho médio de fila nas cabines.

A primeira análise buscou avaliar o efeito da redução dos tempos médios de atendimento nas cabines sobre a capacidade da praça. Para tanto, foram simulados dois cenários correspondentes a um sistema de cobrança exclusivamente manual em todas as cabines. No primeiro cenário, foram adotados os tempos de atendimento registrados pela concessionária no ano de 2003, conforme Tabela 2. No segundo cenário, os tempos de atendimento simulados foram aqueles registrados pela concessionária no ano de 2004, após a mudança nas tarifas e o treinamento dos arrecadadores, conforme Tabela 3. O segundo cenário, portanto, representa a operação da praça com os menores tem- pos de atendimento.

Os resultados foram avaliados para duas composições de tráfego: (i) fluxos compostos somente por automóveis e (ii) fluxos compostos por 70\% de automóveis e 30\% de caminhões. A fração de $30 \%$ de caminhões corresponde à proporção máxima de caminhões no fluxo registrada nos bancos de dados da concessionária.

Os resultados para o primeiro cenário, representativo da operação com os maiores tempos médios de atendimento, são mostrados nas Figuras 2 a 5. A Figura 2 mostra que, para um fluxo composto apenas por automóveis, a capacidade da praça corresponde a 1160 veículos/h. Para um fluxo de entrada próximo à capacidade da praça, a fila média nas cabines é de aproxi-

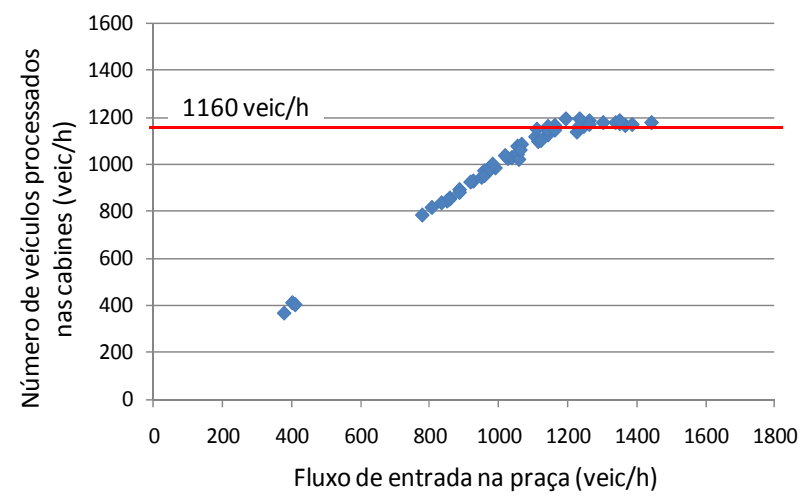

Figura 2. Veículos processados nas cabines para fluxo composto apenas por automóveis, com maiores tempos de atendimento

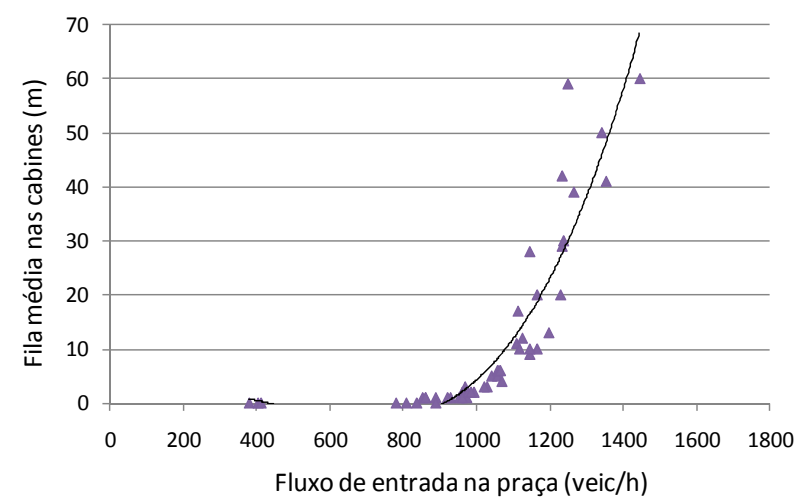

Figura 3. Fila média nas cabines para fluxo composto apenas por automóveis, com maiores tempos de atendimento

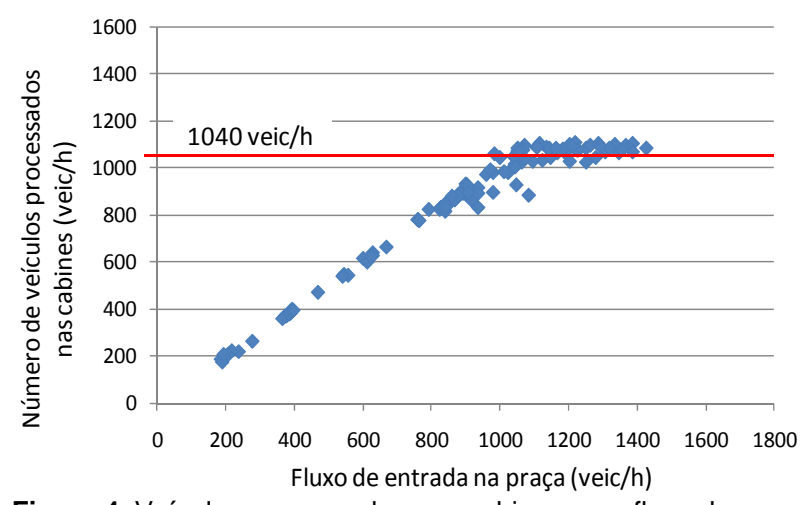

Figura 4. Veículos processados nas cabines para fluxo de automóveis e caminhões, com maiores tempos de atendimento 


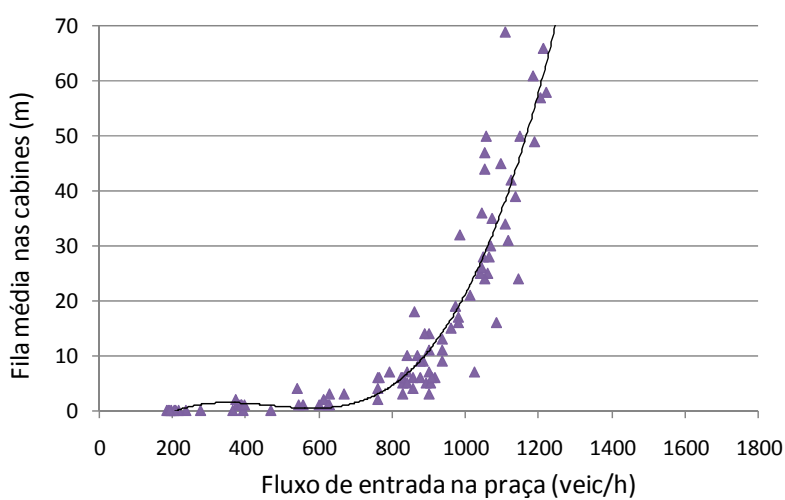

Figura 5. Fila média nas cabines para fluxo composto por automóveis e caminhões, com maiores tempos de atendimento

madamente 11 metros, conforme mostrado pela Figura 3. A simulação do cenário com fluxo constituído por $70 \%$ de automóveis e 30\% de caminhões indicou uma capacidade total da praça igual a 1040 veículos/h (Figura 4). Para esta composição de tráfego, filas médias esperadas para fluxos próximos à capacidade são de aproximadamente 25 metros (Figura 5).

Os resultados para o segundo cenário, representativo da operação com os menores tempos de atendimento, são mostrados nas Figuras 6 a 9. O cenário de simulação no qual a frota era constituída apenas por automóveis indicou uma capacidade total da praça correspondente a 1360 veículos/h. Para um fluxo composto por $70 \%$ de automóveis e 30\% de caminhões, a capacidade da praça corresponde a 1240 veículos/h. As Figuras 7 e 9 apresentam as tendências de crescimento das filas na praça, para as duas composições de tráfego simuladas no segundo cenário.

Observa-se que, com a redução nos tempos de atendimento, há um acréscimo na capacidade de processamento da praça de $17 \%$ para fluxos compostos unicamente por automóveis (de 116 para 136 veic/h/cabine) e de $19 \%$ para fluxos compostos por automóveis e caminhões (de 104 para 124 veic/h/cabine). Acréscimos de $17 \%$ e $19 \%$ sobre a capacidade das praças são bastante significativos. Entretanto, percebe-se que, ao manter a forma de cobrança manual, o potencial de melhoria no desempenho operacional da praça em decorrência de variações nas tarifas e de um aumento de produtividade é limitado. Mudanças nas condições tecnológicas de cobrança tendem a apresentar potenciais maiores de melhorias operacionais, sendo objeto da próxima análise deste trabalho.

Assim, a segunda análise buscou avaliar a influência da utilização de cobrança eletrônica nas condições de operação da praça de pedágio. Para tanto, foram construídos cenários com $10 \%$, 30\% e $40 \%$ de adesão dos usuários a este tipo de cobrança. O valor de $10 \%$ é a taxa média de adesão atualmente encontrada na concessionária. Os resultados foram avaliados para fluxos

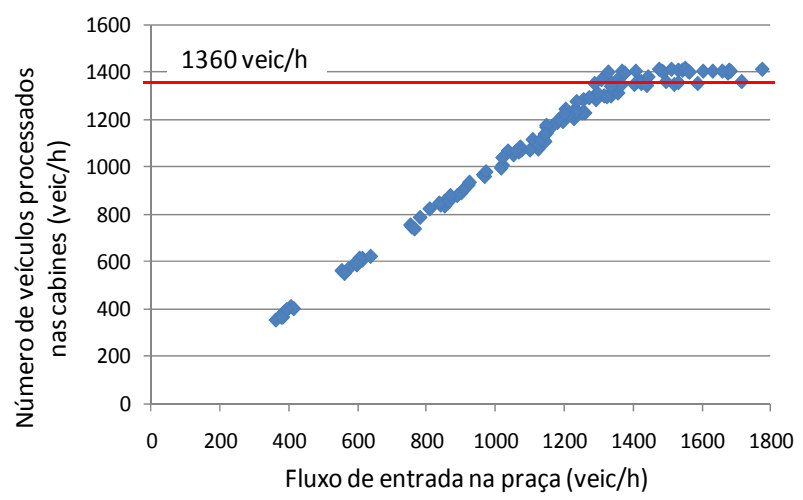

Figura 6. Veículos processados nas cabines para fluxo composto apenas por automóveis, com menores tempos de atendimento

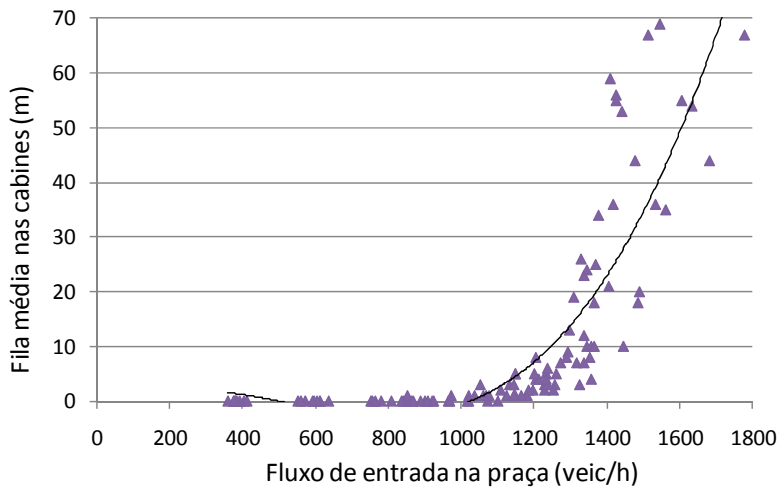

Figura 7. Fila média nas cabines para fluxo composto apenas por automóveis, com menores tempos de atendimento

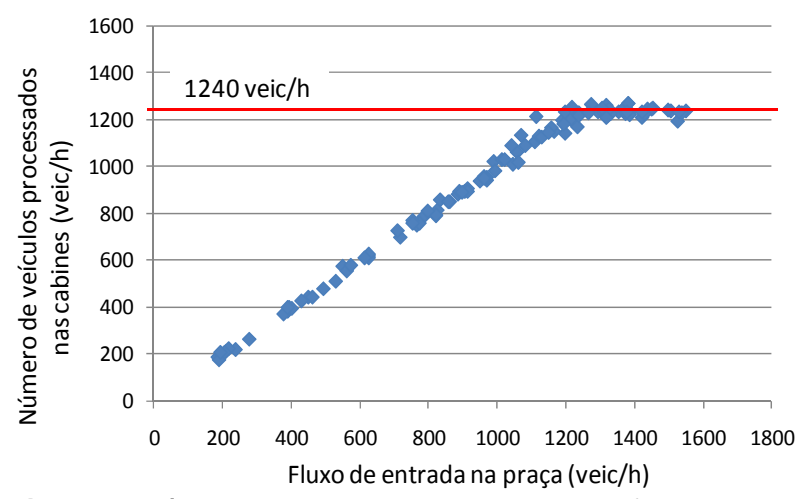

Figura 8. Veículos processados nas cabines para fluxo de automóveis e caminhões, com menores tempos de atendimento

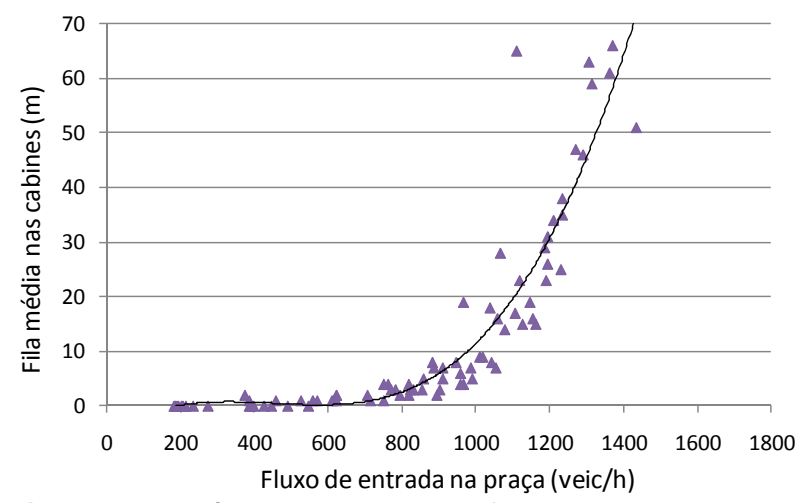

Figura 9. Fila média nas cabines para fluxo composto por automóveis e caminhões, com menores tempos de atendimento

compostos exclusivamente por automóveis, sendo mostrados nas Figuras 10 a 15. 


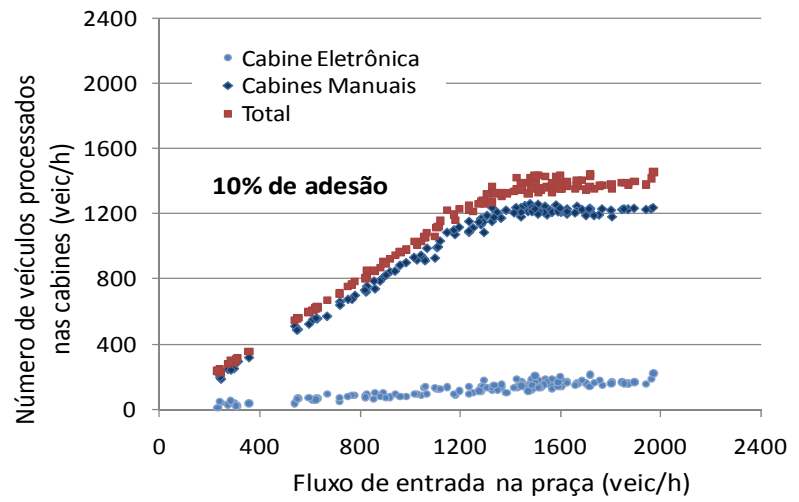

Figura 10. Veículos processados nas cabines para $10 \%$ de adesão à cobrança eletrônica

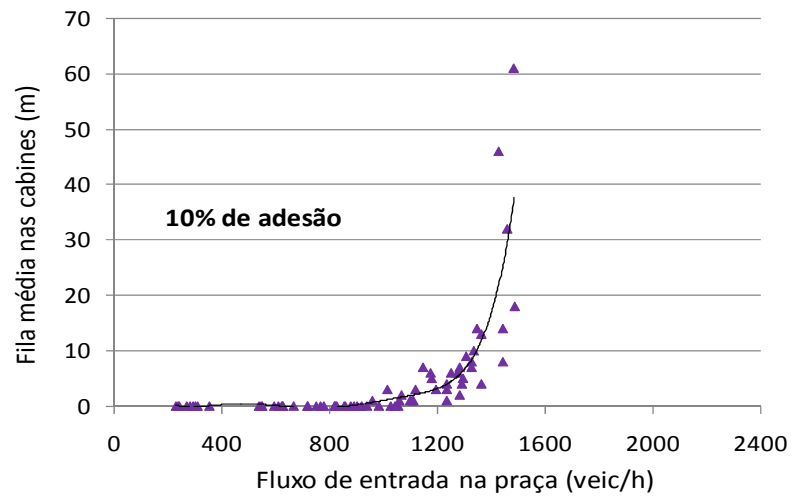

Figura 11. Fila média nas cabines para $10 \%$ de adesão ao sistema de cobrança eletrônica

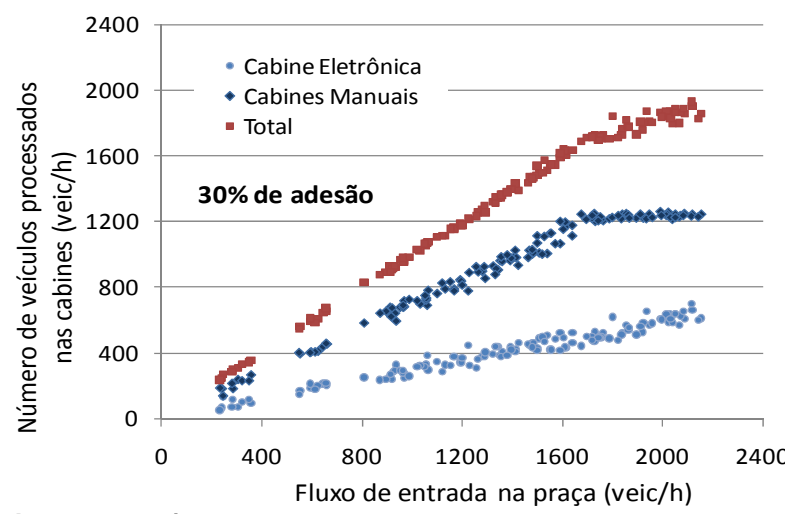

Figura 12. Veículos processados nas cabines para $30 \%$ de adesão à cobrança eletrônica

Analisando os resultados, pode-se perceber que uma taxa de $10 \%$ de adesão dos usuários à cobrança eletrônica exerce um efeito pouco significativo sobre as condições operacionais da praça de pedágio. A capacidade da praça, de cerca de 1360 veículos/h com todas as cabines manuais, sofre um pequeno acréscimo, atingindo cerca de 1400 veículos/h, conforme mostrado na Figura 10. Por outro lado, taxas de adesão maiores exercem impactos bastante pronunciados nas condições de operação.

As Figuras 11, 13 e 15 mostram que, para um mesmo fluxo de entrada na praça, o comprimento médio de fila nas cabines varia muito em função da taxa de adesão à cobrança eletrônica. Para um fluxo de 1400 veículos/h, por exemplo, a fila média é de cerca de 8 metros quando a taxa de adesão é de $10 \%$, diminuindo para aproximadamente 3 metros para uma adesão de

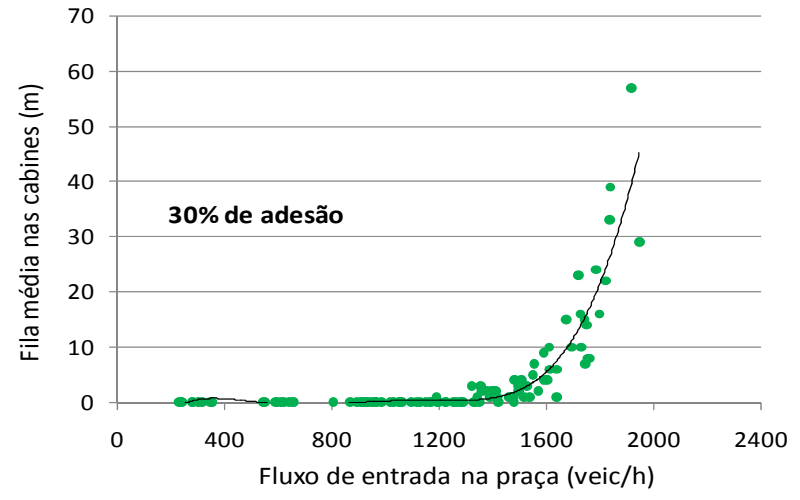

Figura 13. Fila média nas cabines para $10 \%$ de adesão ao sistema de cobrança eletrônica

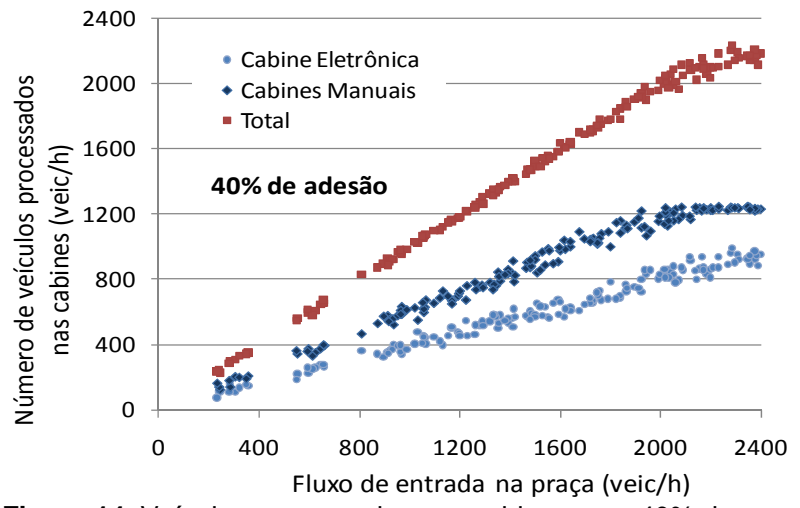

Figura 14. Veículos processados nas cabines para $40 \%$ de adesão à cobrança eletrônica

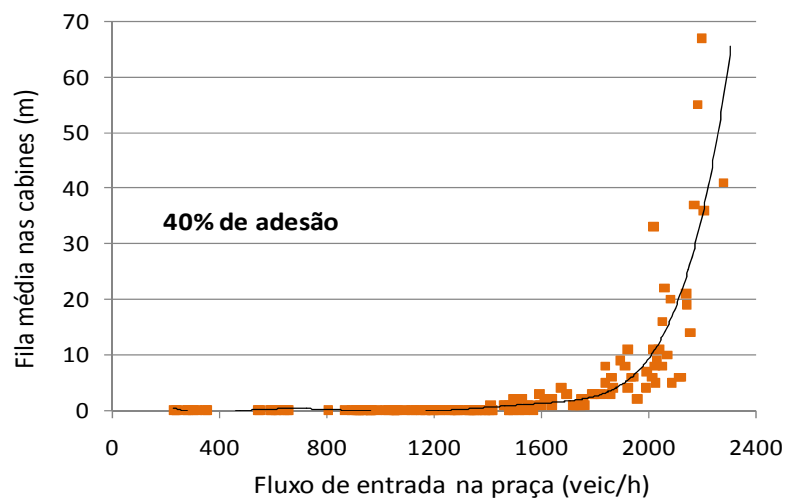

Figura 15. Fila média nas cabines para $40 \%$ de adesão ao sistema de cobrança eletrônica

$30 \%$ e ficando próxima a zero quando a taxa de adesão aumenta para $40 \%$, refletindo uma melhora nas condições de conforto dos usuários que utilizam a praça.

A concessionária fornecedora dos dados desta pesquisa, buscando atender a requisitos referentes a questões contratuais da concessão, estabeleceu como objetivo a operação com filas médias de até 4 veículos. Considerando-se que o espaço ocupado por um automóvel em fila corresponde a aproximadamente 6 metros, o comprimento médio de fila, em um fluxo composto somente por automóveis, é de cerca de 24 metros. 


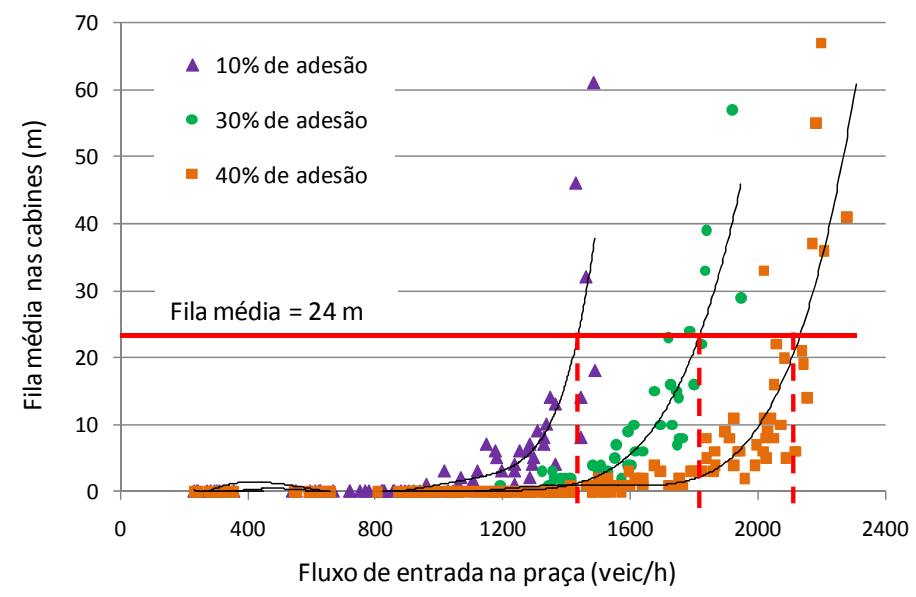

Figura 16. Fila média nas cabines para diferentes taxas de adesão à cobrança eletrônica

Como mostrado na Figura 16, filas médias de 24 metros podem ser alcançadas com diferentes taxas de fluxo, conforme a adesão dos usuários à cobrança eletrônica. Caso a taxa de adesão à cobrança eletrônica corresponda a $10 \%$ dos usuários, cenário representativo da situação atual da concessionária, o fluxo de entrada na praça que resulta em uma fila média de 24 metros é de aproximadamente 1400 veículos/h. Este valor é semelhante à capacidade estimada para operação com todas as cabines manuais. Para uma taxa de adesão de $30 \%$ dos usuários, este mesmo comprimento de fila é alcançado com fluxos de cerca de 1800 veículos/h. Com o aumento da taxa de adesão para $40 \%$, o fluxo admissível para este comprimento de fila nas cabines sofre um acréscimo de aproximadamente $50 \%$, passando para cerca de 2100 veículos/h.

\section{CONCLUSÕES}

As praças de pedágio são as estruturas através das quais as empresas concessionárias realizam a cobrança de tarifas aos usuários, como contrapartida aos investimentos em conservação e ampliação da malha concedida. A imagem de uma concessionária está, portanto, fortemente associada à qualidade do serviço prestado nas praças.

O desempenho operacional de uma praça de pedágio depende de sua capacidade de atendimento, que está fortemente relacionada a fatores como formas de cobrança praticadas, intensidade e composição do fluxo de tráfego que utiliza a rodovia, valores de tarifas, etc.

Este artigo apresentou uma análise do desempenho de uma praça de pedágio frente a diferentes condições de operação. Foram testados os impactos de dois tipos de medidas: (i) treinamento de arrecadadores, de forma a aumentar a eficiência da cobrança manual, e (ii) utilização da cobrança eletrônica de pedágio.

Existe um potencial de incremento no desempenho das praças associado ao treinamento de arrecadadores e à adoção de tarifas que facilitem o troco. Neste estu- do melhorias associadas a estas medidas corresponderam a um aumento de até 19\% na capacidade da praça. Melhorias mais significativas de desempenho, entretanto, podem ser atingidas com o aumento da adesão dos usuários ao sistema de cobrança eletrônica de pedágio.

As condições testadas demonstraram que a manutenção de um indicador estabelecido pela concessionária para a operação das praças (fila média de 4 veículos) pode ser mantida mesmo com volumes crescentes de tráfego, através do aumento da adesão dos usuários à cobrança eletrônica. O esforço de ampliar a adesão de usuários à cobrança eletrônica pode garantir a manutenção de tempos de atendimento adequados nas praças de pedágio, mesmo com significativos aumentos de volumes de tráfego, sem a necessidade de investimentos em ampliação de infraestrutura.

Para os objetivos deste trabalho, a simulação mostrou-se uma ferramenta importante e de grande utilidade para avaliar estratégias operacionais de praças de pedágio. Análises equivalentes às apresentadas neste trabalho podem abranger outras condições não testadas, como um maior número de cabines dedicadas à cobrança eletrônica, o uso de cabines de cobrança mista, composições variadas de fluxo de tráfego, entre outras. Estudos desta natureza possibilitam a análise do desempenho de diferentes medidas gerenciais e políticas operacionais antes que estas sejam colocadas em prática, subsidiando decisões operacionais e políticas de investimento das operadoras.

\section{AGRADECIMENTOS}

Os autores agradecem ao Consórcio Univias pelo apoio na obtenção dos dados de campo. Agradecimentos também ao CNPq e CAPES pelo apoio através da concessão de bolsas de pesquisa.

\section{REFERÊNCIAS BIBLIOGRÁFICAS}

Araújo, J. J. (2001) Características Operacionais de Praças de Arrecadação de Pedágio. Dissertação (Mestrado), 104 p., Escola de Engenharia de São Carlos, Universidade de São Paulo, São Carlos. 
Araújo, J. J. e J. R. Setti (2006) Caracterização Operacional de Praças de Pedágio do Estado de São Paulo. Transportes, v. 14, n. 1, p. 3344.

Aycin, M. F. (2006) Simple Methodology for Evaluating Toll Plaza Operations. Transportation Research Record, v. 1988, p. 92-101.

DNIT (2006) Manual de Estudos de Tráfego - IPR723. Departamento Nacional de Infra-Estrutura de Transportes, Ministério dos Transportes, Brasília, DF.

Lin, F. e C. Su (1994) Level-of-Service Analysis of Toll Plazas on Freeway Main Lines. Journal of Transportation Engineering, v.120, n.2, p.246-263.

Oliveira, M.L., J.M.R. Neto, e H.B.B. Cybis (2003) A Influência do Tamanho das Filas na Capacidade de Atendimento das Praças de Pedágio. Anais do XVII Congresso de Pesquisa e Ensino em Transportes, ANPET, Rio de Janeiro, v.2, p.1264-1275.

Oliveira, M.L. (2004) Fatores Intervenientes na Capacidade de Atendimento de Praças de Pedágio. Dissertação (Mestrado), 137 p., Programa de Pós-Graduação em Engenharia de Produção - UFRGS, Porto Alegre.

Oliveira, M.L. (2009) Método para Determinação de Nível de Serviço em Praças de Pedágio. Tese (Doutorado), 138 p., Programa de PósGraduação em Engenharia de Produção - UFRGS, Porto Alegre.

PTV (2006) VISSIM v.4.30 User Manual. PTV - Planung Transport Verkehr AG.

Wiedemann, R. (1991) Modeling of RTI-Elements on Multi-Lane Roads. In: Advanced Telematics in Road Transport. Edited by Commission of the European Community, DB XIII, Brussels.

Woo, T.H. e L. H. Hoel (1991) Toll Plaza Capacity and Level of Service. Transportation Research Record 1320, p.119-127. Transportation Research Board, Washington, D.C. 